\title{
Parthenolide induces superoxide anion production by stimulating EGF receptor in MDA-MB-231 breast cancer cells
}

\author{
A. D'ANNEO ${ }^{1}$, D. CARLISI ${ }^{2}$, S. EMANUELE $^{2}$, G. BUTTITTA $^{2}$, R. DI FIORE ${ }^{1}$, \\ R. VENTO ${ }^{1,3}$, G. TESORIERE ${ }^{1,3}$ and M. LAURICELLA ${ }^{2}$ \\ ${ }^{1}$ Laboratory of Biochemistry, Department of Biological, Chemical and Pharmaceutical Sciences and Technologies, \\ ${ }^{2}$ Laboratory of Biochemistry, Department of Experimental Biomedicine and Clinical Neurosciences, Polyclinic, \\ University of Palermo, Palermo, Italy; ${ }^{3}$ Sbarro Institute for Cancer Research and Molecular Medicine, \\ College of Science and Technology, Temple University, Philadelphia, PA 19122, USA
}

Received July 25, 2013; Accepted September 10, 2013

DOI: $10.3892 /$ ijo.2013.2137

\begin{abstract}
The sesquiterpene lactone parthenolide (PN) has recently attracted considerable attention because of its antimicrobial, anti-inflammatory and anticancer effects. However, the mechanism of its cytotoxic action on tumor cells remains scarcely defined. We recently provided evidence that the effect exerted by PN in MDA-MB-231 breast cancer cells was mediated by the production of reactive oxygen species (ROS). The present study shows that PN promoted the phosphorylation of EGF receptor (phospho-EGFR) at Tyr1173, an event which was observed already at $1 \mathrm{~h}$ of incubation with $25 \mu \mathrm{M}$ PN and reached a peak at 8-16 h. This effect seemed to be a consequence of ROS production, because $\mathrm{N}$-acetylcysteine (NAC), a powerful ROS scavenger, prevented the increment of phosphoEGFR levels. In addition fluorescence analyses performed using dihydroethidium demonstrated that PN stimulated the production of superoxide anion already at 2-3 $\mathrm{h}$ of incubation and the effect further increased prolonging the time of treatment, reaching a peak at 8-16 h. Superoxide anion production was markedly hampered by apocynin, a well known NADPH oxidase (NOX) inhibitor, suggesting that the effect was dependent on NOX activity. The finding that AG1478, an EGFR kinase inhibitor, substantially blocked both EGFR phosphory-
\end{abstract}

Correspondence to: Professor Marianna Lauricella, Laboratory of Biochemistry, Department of Experimental Biomedicine and Clinical Neurosciences, Polyclinic, University of Palermo, Via del Vespro 129, 90127 Palermo, Italy

E-mail: marianna.lauricella@unipa.it

Abbreviations: DHE, dihydroethidium; EGF, epidermal growth factor; rhEGF, recombinant human EGF; EGFR, epidermal growth factor receptor; ER $\alpha$, estrogen receptor $\alpha$; HER, human epidermal growth factor receptor; NAC, N-acetylcysteine; NOX, NADPH oxidase; PN, parthenolide; PR, progesterone receptor; ROS, reactive oxygen species; TNBC, triple-negative breast cancer

Key words: parthenolide, epidermal growth factor receptor, NADPH oxidase, breast cancer cells lation and superoxide anion production strongly suggested that phosphorylation of EGFR can be responsible for the activation of NOX with the consequent production of superoxide anion. Therefore, EGFR phosphorylation can exert a key role in the production of superoxide anion and ROS induced by PN in MDA-MB-231 cells.

\section{Introduction}

PN is a sesquiterpene lactone, derived from the medicinal plant feverfew Tanacetum parthenium, which is conventionally used to treat migraine and rheumatoid arthritis (1). In addition it has been shown that PN exhibits anticancer activity in several cancer cell types, such as colorectal cancer (2), pancreatic cancer (3), prostate cancer (4), multiple myeloma (5), osteosarcoma and melanoma (6).

Recently we have demonstrated that PN exerted a marked cytotoxic effect on MDA-MB-231 cells, a triple-negative breast cancer cell line (7). This effect was not prevented by the caspase inhibitor z-VAD-fmk, while was counteracted by the ROS scavenger NAC. Cytotoxic action was primarily correlated with generation of ROS, which in turn were responsible for induction of autophagy, dissipation of $\Delta \psi \mathrm{m}$ and necrotic events.

Epidermal growth factor receptor (EGFR), also known as human epidermal growth factor receptor (HER1 or erbB1), is a member of a family of tyrosine kinase receptors which includes three additional receptors: HER2 (erbB2), HER3 (erbB3) and HER4 (erbB4) (8). In response to EGF binding, EGFR forms homo- or heterodimers with other HER family members, followed by autophosphorylation of key tyrosine residues located within the tyrosine kinase domain (8). Once activated, EGFR can promote proliferation and survival such as migration, invasion, differentiation, inhibition of apoptosis and angiogenesis (9-11).

EGFR and related family members have been found to be mutated or amplified in a number of human lung and breast cancers and this event has been associated with poor prognosis, short survival and poor response to therapy $(12,13)$.

Data from several research groups have shown that activation of EGFR can be involved in the production of ROS (14-16). 
Moreover, it has been reported that endogenous hydrogen peroxide $\left(\mathrm{H}_{2} \mathrm{O}_{2}\right)$, produced as a consequence of EGF binding to EGFR, can be utilized by the cells as a secondary messenger to regulate physiological signal transduction $(17,18)$.

The aim of this study was to ascertain whether the activation of NADPH oxidase (NOX) induced by PN in MDA-MB-231 cells can be mediated by EGFR activation. The results demonstrate that treatment of MDA-MB-231 cells with PN increases the level of the phosphorylated form of EGFR (phospho-EGFR) and that this event is correlated with the activation of NOX and superoxide generation.

\section{Materials and methods}

Chemicals and reagents. All reagents were purchased from Sigma-Aldrich (Milan, Italy), except for recombinant human EGF (rhEGF), which was supplied from Clontech (Palo Alto, CA, USA) and AG1478, supplied from Calbiochem-Merk Millipore (Milan, Italy). PN, apocynin and AG1478 were solubilized in dimethyl sulfoxide (DMSO) and diluted to final concentration in the culture medium. Final concentration of DMSO employed as vehicle never exceeded $0.04 \%$ and had no discernible effects on MDA-MB-231 cells in comparison with the control.

Cell cultures. Human breast carcinoma cell line MDA-MB-231 was provided by 'Istituto Scientifico Tumori' (Genoa, Italy). Cells were grown as monolayer in DMEM medium supplemented with $10 \%(\mathrm{v} / \mathrm{v})$ heat inactivated fetal calf serum (FCS), $2 \mathrm{mM}$ glutamine and $1 \%$ non-essential amino acids, at $37^{\circ} \mathrm{C}$ in a humidified atmosphere containing $5 \% \mathrm{CO}_{2}$. After plating on 96- or 6-well plates, cells were allowed to adhere overnight and then treated with chemicals or vehicle only.

Western blot analysis. Whole cell lysates were prepared as previously reported (19) and protein concentration was determined by Lowry assay (20). Equal amounts of protein samples (50 $\mu \mathrm{g} / \mathrm{lane})$ were run in an SDS polyacrylamide gel electrophoresis, then transferred to a nitrocellulose membrane. Analyses of EGFR and phopho-EGFR were performed using specific antibodies which were provided by Santa Cruz Biotechnology (Santa Cruz, CA, USA). In particular, for phopho-EGFR an antibody recognizing phosphorylated Tyr1173 was used. Then the detection was developed by using a secondary antibody conjugated with alkaline phosphatase. Protein bands were visualized using nitroblue tetrazolium and 5-bromo-4-chloro-3-indoyl-phosphate and their intensity was quantified by densitometric analysis using SMX Image software. The correct protein loading was ascertained by red Ponceau staining and immunoblotting for $\beta$-actin. All the blots shown are representative of at least three separate experiments.

Measurement of superoxide production. The superoxide radical production was assessed by dihydroethidium (DHE) staining. DHE is a fluorochrome that is oxidized by superoxide to fluorescent ethidium that intercalates with nuclear DNA, staining the nucleus with a bright red fluorescence. MDA-MB-231 cells $\left(8 \times 10^{3} /\right.$ well) were incubated with PN or other effectors, then cells were centrifuged at $120 \mathrm{x} \mathrm{g}$ for $5 \mathrm{~min}$ and culture medium was replaced with a solution
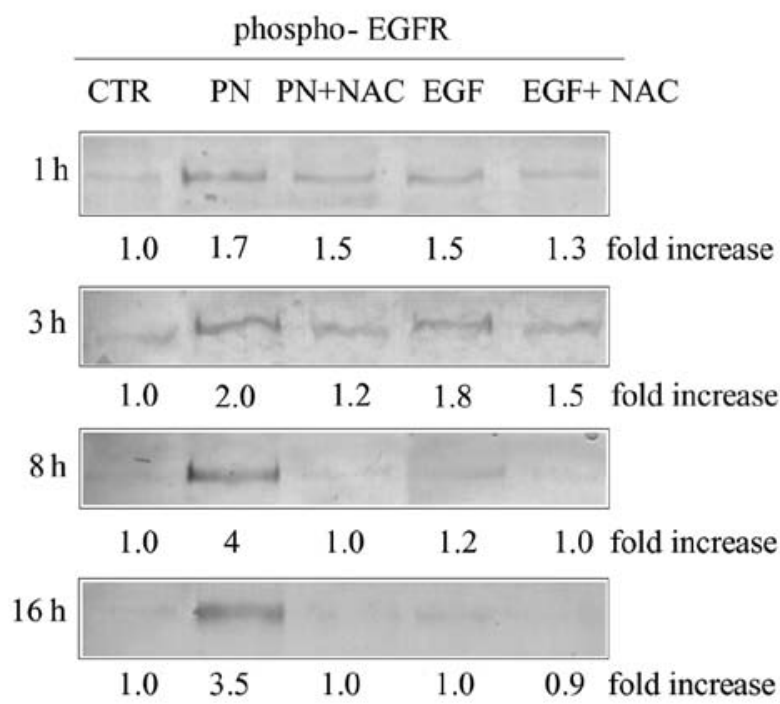

$\beta$-actin $\square=16 \mathrm{~h}$

Figure 1. The effect of PN or rhEGF on EGFR phosphorylation. MDA-MB-231 cells $\left(2 \times 10^{5}\right.$ cells/well) were treated for various times with $25 \mu \mathrm{M}$ PN or $200 \mathrm{ng} / \mathrm{ml} \mathrm{rhEGF}$ without or with $2 \mathrm{mM}$ NAC. At the end cell extracts were prepared and submitted to western blot analysis using a specific antibody recognizing EGFR phosphorylated on Tyr1173. The results are representative of three independent experiments.

of DHE $(20 \mu \mathrm{M})$ in PBS. The incubation was protracted for $10 \mathrm{~min}$ and DHE-positive cells were analysed by fluorescence microscopy using an excitation wavelength of $596 \mathrm{~nm}$ and an emission wavelength of $620 \mathrm{~nm}$. All the images were acquired by Leica Q Fluoro Software. Percentage of DHE-positive cells was evaluated by using ImageJ software.

Statistical analysis. Results are presented as means \pm standard error. Data were analysed using Student's t-test.

\section{Results}

PN stimulates EGFR phosphorylation. In the present study we evaluated whether the exposure of MDA-MB-231 cells to PN resulted in the phosphorylation and activation of EGFR and consequently in the induction of NOX activity.

It is well known that activation of EGFR depends on phosphorylation of the amino acid residue Tyr1173 (21). Therefore, MDA-MB-231 cells were treated with $25 \mu \mathrm{M}$ PN for different times and subjected to western blot analysis to evaluate the level of phospho-EGFR by using an antibody recognizing phospho-Tyr1173. As shown in Fig. 1, the level of phosphoEGFR was increased already at $1 \mathrm{~h}$ of treatment with PN. The effect was enhanced with time reaching the maximum at about $8 \mathrm{~h}$ of treatment, and remaining elevated up to $16 \mathrm{~h}$. Increment of EGFR phosphorylation was prevented by 2 mM NAC, whatever the time of treatment was (Fig. 1), thus suggesting that the effect was a consequence of oxidative stress induction.

The effects of PN on MDA-MB-231 cells were compared with that exerted by recombinant human EGF (rhEGF), a direct EGFR ligand. Treatment of cells with $200 \mathrm{ng} / \mathrm{ml} \mathrm{rhEGF}$ caused phosphorylation of EGFR with a maximum effect 

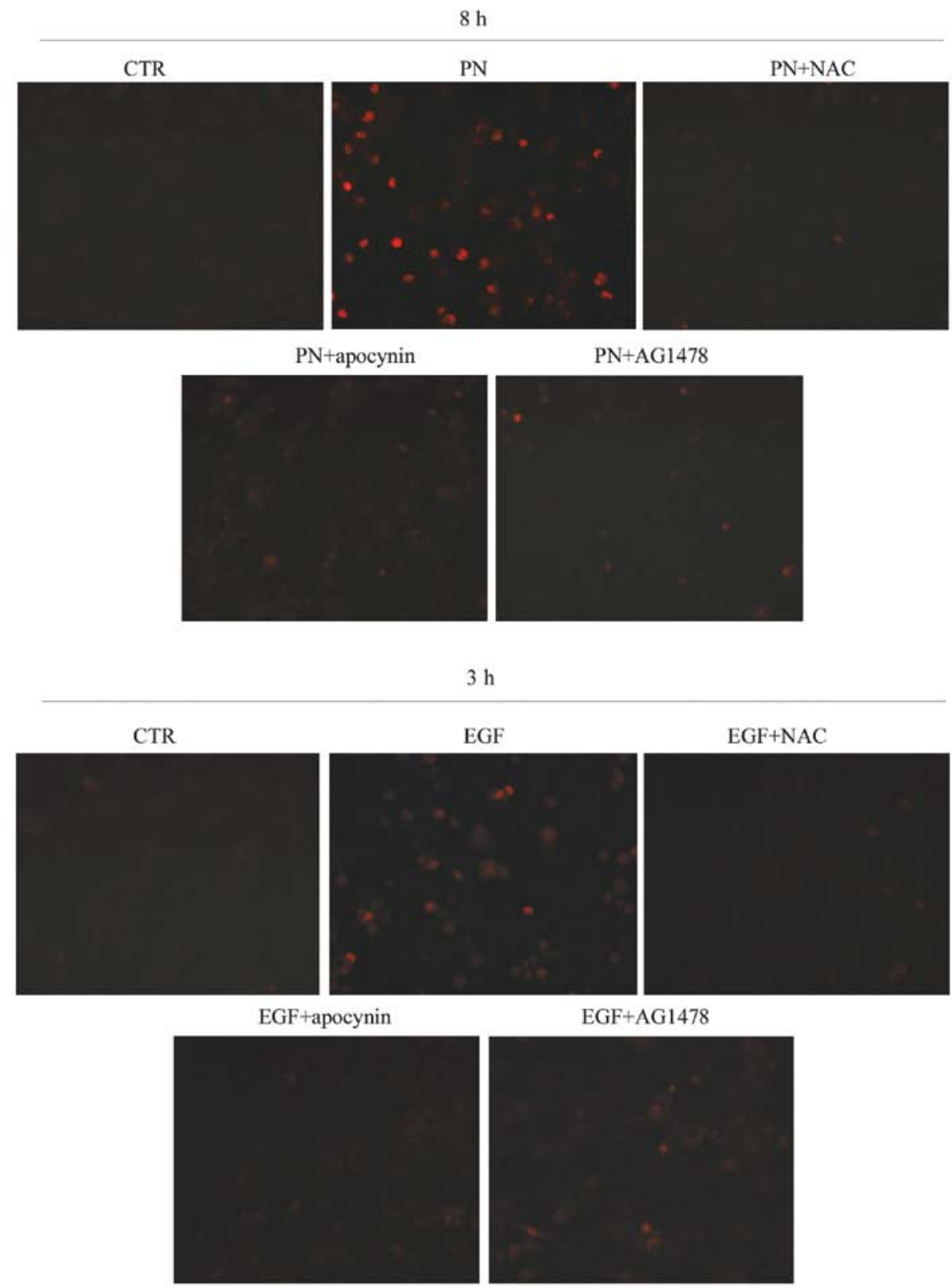

Figure 2. Superoxide anion generation in PN- or rhEGF-treated cells. MDA-MB-231 cells ( $8 \times 10^{3} /$ well) were treated for $8 \mathrm{~h}$ with $25 \mu \mathrm{M}$ PN or for $3 \mathrm{~h}$ with $200 \mathrm{ng} / \mathrm{ml} \mathrm{rhEGF}$, either in the presence or absence of $2 \mathrm{mM} \mathrm{NAC}$ or $100 \mu \mathrm{M}$ apocynin or $20 \mu \mathrm{M}$ AG1478. The plate was then centrifuged at $120 \mathrm{xg}$ for $5 \mathrm{~min}$ and the culture medium replaced with $20 \mu \mathrm{M}$ DHE in PBS. After $10 \mathrm{~min}$ of incubation, DHE-positive cells were analysed by fluorescence microscopy as described in Materials and methods. The results are representative of three independent experiments.

found between 1 and $3 \mathrm{~h}$. Such an effect was much lower than that observed with PN and was only partially reduced by the addition of 2 mM NAC (Fig. 1). Finally treatment with rhEGF, in contrast with PN, did not exert any cytotoxic effect (not shown).

It is noteworthy that treatment of MDA-MB-231 cells with PN or rhEGF did not modify the level of the EGFR (not shown). Therefore, after PN or rhEGF treatment the amount of EGFR remained unchanged, whereas its tyrosine phosphorylation increased.

$P N$ induces production of superoxide anion. ROS include superoxide anion $\left(\mathrm{O}_{2}{ }^{-}\right)$, which is a highly reactive oxygen species and hydrogen peroxide $\left(\mathrm{H}_{2} \mathrm{O}_{2}\right)$. High doses of ROS, in particular superoxide anion, result in oxidative stress, which is implicated in the pathogenesis of a number of diseases and in the cytotoxic action of many drugs (22). NADPH oxidases (NOXs), which are present in phagocytes, but also in other somatic cells, are multicomponent enzymes that catalyze the generation of superoxide anion from oxygen and NADPH (23). NOX4 has been identified as the principal source of superoxide production in MDA-MB-231 cells (24).

In order to ascertain whether PN stimulated NOX activation in MDA-MB-231 cells, we evaluated the effect of the drug on superoxide production by using DHE, a specific fluorescent probe. It was observed that PN induced the appearance of intense red fluorescence, suggesting that the drug induced production of superoxide anion by stimulating NOX activity (Fig. 2). Such an effect was abrogated by either NAC or apocynin, a specific inhibitor of NOX activity (25). 


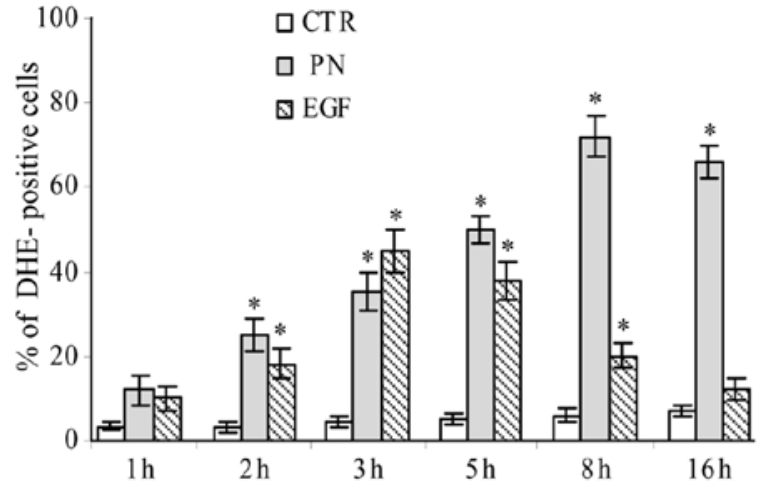

Figure 3. Time course evaluation of superoxide anion production. Cells ( $8 \times 10^{3} /$ well) were treated with $25 \mu \mathrm{M}$ PN or $200 \mathrm{ng} / \mathrm{ml} \mathrm{rhEGF}$ for the indicated times and superoxide anion was measured with DHE as reported in Materials and methods and in Fig. 2. Values are the means of three independent experiments \pm SE. ${ }^{*} \mathrm{p}<0.01$ versus untreated control.

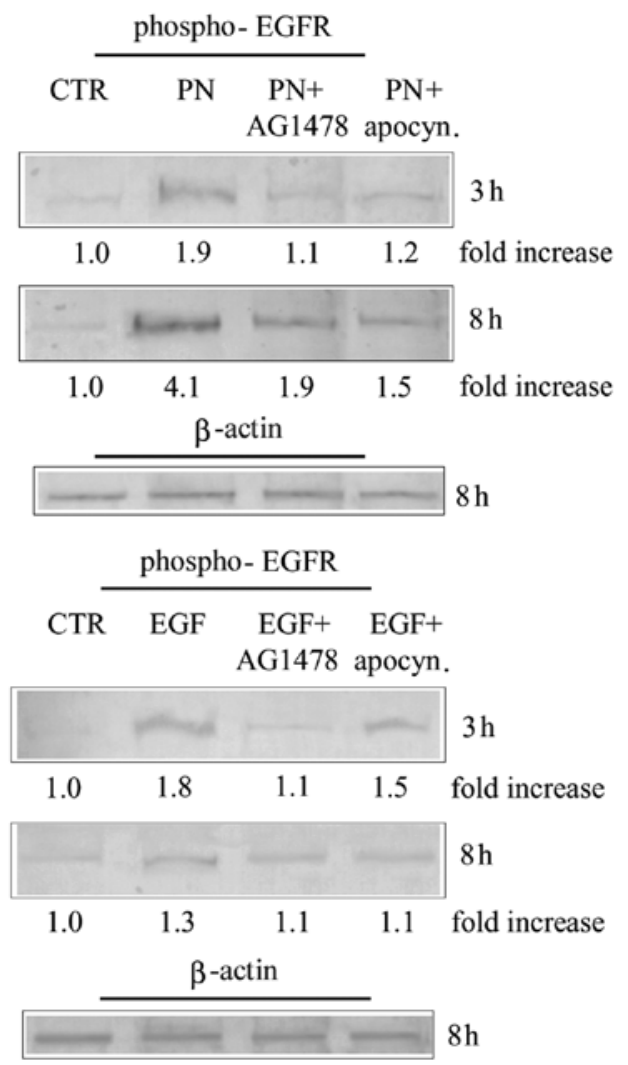

Figure 4. The effect of AG1478 or apocynin on EGFR phosphorylation. MDA-MB-231 cells ( $2 \times 10^{5}$ cells/well) were treated with $25 \mu \mathrm{M}$ PN for $8 \mathrm{~h}$ or $200 \mathrm{ng} / \mathrm{ml} \mathrm{rhEGF}$ for $3 \mathrm{~h}$ either in the presence or absence of $20 \mu \mathrm{M}$ AG1478 or $100 \mu \mathrm{M}$ apocynin. At the end, extracts were prepared and submitted to western blot analysis, using a specific antibody recognizing EGFR phosphorylated on Tyr1173 as described in Materials and methods. The results are representative of three independent experiments.

A time course study showed that the production of superoxide anion increased already after $1 \mathrm{~h}$ of treatment with $25 \mu \mathrm{M}$ PN, reached the maximum at $8 \mathrm{~h}$, when $72 \%$ of cells showed red fluorescence, and maintained a considerable level until 16 h (Fig. 3).

We also evaluated whether rhEGF treatment induced the production of superoxide anion. As shown in Fig. 2, the effect was observed particularly at $3 \mathrm{~h}$ of treatment and was lower than that found in PN-treated MDA-MB-231 cells.

Production of superoxide anion induced by PN is correlated with EGFR activation. In order to ascertain a possible correlation between superoxide anion production and EGFR activation induced by $\mathrm{PN}$ treatment, we performed experiments using AG1478, which is a specific inhibitor of the kinase activity of EGFR (26).

MDA-MB-231 cells were treated for 3 and $8 \mathrm{~h}$ with $25 \mu \mathrm{M}$ $\mathrm{PN}$ in the presence or absence of $20 \mu \mathrm{M}$ AG1478. In order to confirm the specificity of the inhibitory action exerted by AG1478, PN was substituted in some samples with $200 \mathrm{ng} / \mathrm{ml}$ rhEGF. Results reported in Fig. 4 show that the increase in the level of phospho-EGFR induced by both PN and rhEGF was prevented by AG1478. Then we evaluated the effect of AG1478 on the production of superoxide anion in MDA-MB-231 cells stimulated with PN or rhEGF. Results shown in Fig. 2 demonstrate that the addition of AG1478 to PN or rhEGF prevented, after incubation with DHE, the production of cells with red fluorescence. These results suggest that phosphorylation and activation of EGFR induced by PN were closely correlated with stimulation of NOX and production of superoxide anion.

\section{Discussion}

EGFR is a member of the ErbB family of tyrosine kinases, which is involved in the regulation of proliferation and differentiation primarily of epithelial cell types (27). Following ligand binding, the EGFR dimerizes and the intracellular tyrosine kinase region is activated, causing receptor tyrosine autophosphorylation and transphosphorylation of another receptor monomer (27). These events lead to the recruitment and phosphorylation of several intracellular substrates and the subsequent transmission of extracellular signals to the nucleus via an intracellular signaling network (27).

EGFR activation plays important roles in the stimulation of cell growth, survival, migration and differentiation $(9,11)$. EGFR and related family members have been found to be mutated or amplified in a number of human lung and breast cancers $(12,13,28,29)$. Our study was performed on MDA-MB-231 cells, a 'triple-negative' breast cancer cell line which lacks estrogen receptor $\alpha(\mathrm{ER} \alpha)$, progesterone receptor and HER2 (29). Instead MDA-MB-231 cells are known to contain high levels of EGFR (HER1) $(29,30)$. This observation has been correlated with the absence in these cells of $\mathrm{ER} \alpha$, because an inverse relationship has been demonstrated between the presence of ER $\alpha$ and the level of EGFR (31).

In the present study we provide evidence that in MDA-MB-231 cells PN increased the level of the phosphorylated form of EGFR. This effect was remarkable between 8 and $16 \mathrm{~h}$ of treatment. Furthermore, the production of phosphoEGFR was prevented by NAC, a general ROS scavenger. Such a result suggests that $\mathrm{PN}$ effect was mediated by ROS generation. This conclusion agrees with our previous finding (7) that in MDA-MB-231 cells PN strongly induced production of ROS already in the first hours of treatment (1-3 h).

It has been shown also previously that a correlation exists between enhancement of ROS and phosphorylation of EGFR (32), and suggested that ROS could be responsible for the 
reversible oxidization of thiol groups of the catalytic site of protein phosphatases, involved in dephosphorylation of EGFR $(33,34)$. As a consequence phosphatases are inactivated and EGFR is maintained in the phosphorylated active form (34). However, other authors demonstrated that $\mathrm{H}_{2} \mathrm{O}_{2}$ directly can modify a specific cysteine residue (Cys797) of EGFR to sulfenic acid in the active site of the receptor, enhancing tyrosine kinase activity of EGFR (35).

Our results also show that $\mathrm{PN}$ increased the production of anion superoxide, reaching very high levels between 8 and $16 \mathrm{~h}$. The observation that the production of superoxide anion induced by PN was prevented by the addition of apocynin, an inhibitor of NOX, suggests the involvement of NOX in the production of superoxide.

Our study provides evidence that addition of AG1478, a specific inhibitor of EGFR tyrosine kinase, was capable of inhibiting the effects of PN both on EGFR phosphorylation and on the production of superoxide anion. Therefore it seems that phosphorylation of EGFR and activation of NOX are closely correlated. Such a correlation has been suggested by many other authors. In particular Tamàs et al (36) have shown that EGFR activates Rac1, a member of Rac GTPase involved in activation of the non-phagocytic NADPH oxidases (23), by phosphorylating and associating with Vav2 factor. Moreover, Sheng et al (37) reported that ofloxacin caused intracellular ROS production by activating EGFR-Rac1-NOX2 pathway.

Collectively, our results led us to the following conclusions: PN generates already in the first phase of treatment (1-3 h) production of ROS; ROS activate phosphorylation of EGFR and this causes stimulation of NOX and new production of ROS. These considerations suggest that the mechanism induced by PN is based on the creation of a positive feedback loop, which through the involvement of the EGFR sustains for a long period of time $(16 \mathrm{~h})$ activation of NOX and production of ROS.

\section{Acknowledgements}

This study was supported by grants from: Italian Ministry of Education, University and Research (MIUR) ex-60\%, 2007, and partially funded by European Regional Development Fund, European Territorial Cooperation 2007-2013, CCI 2007 CB 163 PO 037, OP Italia-Malta 2007-2013. Dr D. Carlisi is a recipient of a grant by 'Italian Ministry of Education, University and Research' (MIUR). Dr G. Buttitta is a PhD student supported by 'Italian Ministry of Education, University and Research' (MIUR).

\section{References}

1. Ghantous A, Sinjab A, Herceg Z and Darwiche N: Parthenolide: from plant shoots to cancer roots. Drug Discov Today 18: 894-905, 2013.

2. Kim SL, Trang KT, Kim SH, Kim IH, Lee SO, Lee ST, Kim DG and Kim SW: Parthenolide suppresses tumor growth in a xenograft model of colorectal cancer cells by inducing mitochondrial dysfunction and apoptosis. Int J Oncol 41: 1547-1553, 2012.

3. Yip-Schneider MT, Nakshatri H, Sweeney CJ, Marshall MS, Wiebke EA and Schmidt CM: Parthenolide and sulindac cooperate to mediate growth suppression and inhibit the nuclear factor-kappa B pathway in pancreatic carcinoma cells. Mol Cancer Ther 4: 587-594, 2005 .
4. Sun Y, St Clair DK, Xu Y, Crooks PA and St Clair WH: A NADPH oxidase-dependent redox signaling pathway mediates the selective radiosensitization effect of parthenolide in prostate cancer cells. Cancer Res 70: 2880-2890, 2010.

5. Wang W, Adachi M, Kawamura R, Sakamoto H, Hayashi T, Ishida T, Imai K and Shinomura Y: Parthenolide-induced apoptosis in multiple myeloma cells involves reactive oxygen species generation and cell sensitivity depends on catalase activity. Apoptosis 11: 2225-2235, 2006.

6. D'Anneo A, Carlisi D, Lauricella M, Emanuele S, Di Fiore R, Vento R and Tesoriere G: Parthenolide induces caspase-independent and AIF-mediated cell death in human osteosarcoma and melanoma cells. J Cell Physiol 228: 952-967, 2013.

7. D'Anneo A, Carlisi D, Lauricella M, Puleio R, Martinez R, Di Bella S, Di Marco P, Emanuele S, Di Fiore R, Guercio A, Vento $\mathrm{R}$ and Tesoriere G: Parthenolide generates reactive oxygen species and autophagy in MDA-MB-231 cells. A soluble parthenolide analogue inhibits tumour growth and metastasis in a xenograft model of breast cancer. Cell Death Dis (In press).

8. Bazley LA and Gullick WJ: The epidermal growth factor receptor family. Endocr Relat Cancer 12: 17-27, 2005.

9. Hölsken A, Gebhardt M, Buchfelder M, Fahlbusch R, Blümcke I and Buslei R: EGFR signaling regulates tumor cell migration in craniopharyngiomas. Clin Cancer Res 17: 4367-4377, 2011.

10. Zhang J, Li H, Wang J, Dong Z, Mian S and Yu FS: Role of EGFR transactivation in preventing apoptosis in Pseudomonas aeruginosa-infected human corneal epithelial cells. Invest Ophthalmol Vis Sci 45: 2569-2576, 2004.

11. van Cruijsen H, Giaccone G and Hoekman K: Epidermal growth factor receptor and angiogenesis: opportunities for combined anticancer strategies. Int J Cancer 118: 883-888, 2006.

12. Macias A, Azavedo E, Hagerstrom T, Klintenberg C, Perez R and Skoog L: Prognostic significance of the receptor for epidermal growth factor in human mammary carcinomas. Anticancer Res 7: 459-464, 1987

13. Sequist LV, Joshi VA, Jänne PA, Muzikansky A, Fidias P, Meyerson M, Haber DA, Kucherlapati R, Johnson BE and Lynch TJ: Response to treatment and survival of patients with non-small cell lung cancer undergoing somatic EGFR mutation testing. Oncologist 12: 90-98, 2007.

14. Bae YS, Kang SW, Seo MS, Baines IC, Tekle E, Chock PB and Rhee SG: Epidermal growth factor (EGF)-induced generation of hydrogen peroxide. Role in EGF receptor-mediated tyrosine phosphorylation. J Biol Chem 272: 217-221, 1997.

15. Cuddihy SL, Winterbourn CC and Hampton MB: Assessment of redox changes to hydrogen peroxide-sensitive proteins during EGF signaling. Antioxid Redox Signal 15: 167-174, 2011.

16. Truong TH and Carroll KS: Redox regulation of epidermal growth factor receptor signaling through cysteine oxidation. Biochemistry 51: 9954-9965, 2012 .

17. Chiarugi P, Pani G, Giannoni E, Taddei L, Colavitti R, Raugei G, Symons M, Borrello S, Galeotti T and Ramponi G: Reactive oxygen species as essential mediators of cell adhesion: the oxidative inhibition of a FAK tyrosine phosphatase is required for cell adhesion. J Cell Biol 161: 933-944, 2003.

18. Jagadeesha DK, Takapoo M, Banfi B, Bhalla RC and Miller FJ Jr: Nox1 transactivation of epidermal growth factor receptor promotes $\mathrm{N}$-cadherin shedding and smooth muscle cell migration. Cardiovasc Res 93: 406-413, 2012.

19. Giuliano M, Lauricella M, Calvaruso G, Carabillò $M$, Emanuele S, Vento R and Tesoriere G: The apoptotic effects and synergistic interaction of sodium butyrate and MG132 in human retinoblastoma Y79 cells. Cancer Res 59: 5586-5595, 1999.

20. Lowry OH, Rosebrough NJ, Farr AL and Randall RJ: Protein measurement with the Folin phenol reagent. J Biol Chem 193: 265-275, 1951 .

21. Voldborg BR, Damstrup L, Spang-Thomsen M and Poulsen HS: Epidermal growth factor receptor (EGFR) and EGFR mutations, function and possible role in clinical trials. Ann Oncol 8: 1197-1206, 1997.

22. Paletta-Silva R, Rocco-Machado N and Meyer-Fernandes JR: NADPH oxidase biology and the regulation of tyrosine kinase receptor signaling and cancer drug cytotoxicity. Int J Mol Sci 14: 3683-3704, 2013.

23. Hordijk PL: Regulation of NADPH oxidases: the role of Rac proteins. Circ Res 98: 453-462, 2006.

24. Boudreau HE, Casterline BW, Rada B, Korzeniowska A and Leto TL: Nox4 involvement in TGF-beta and SMAD3-driven induction of the epithelial-to-mesenchymal transition and migration of breast epithelial cells. Free Radic Biol Med 53: 1489-1499, 2012. 
25. Wu F, Tyml K and Wilson JX: iNOS expression requires NADPH oxidase-dependent redox signaling in microvascular endothelial cells. J Cell Physiol 117: 207-214, 2008.

26. Zhua XF, Liua ZC, Xiea BF, Lia ZM, Fenga GK, Yangb D and Zeng YX: EGFR tyrosine kinase inhibitor AG1478 inhibits cell proliferation and arrests cell cycle in nasopharyngeal carcinoma cells. Cancer Lett 169: 27-32, 2001.

27. Schlessinger J: Ligand-induced, receptor-mediated dimerization and activation of EGF receptor. Cell 110: 669-672, 2002.

28. Kosaka T, Yatabe Y, Endoh H, Kuwano H, Takahashi T and Mitsudomi T: Mutations of epidermal growth factor receptor gene in lung cancer: biological and clinical implications. Cancer Res 64: 8919-8923, 2004

29. Rampaul RS, Pinder SE, Nicholson RI, Gullick WJ, Robertson JF and Ellis IO: Clinical value of epidermal growth factor receptor expression in primary breast cancer. Adv Anat Pathol 12: 271-273, 2005.

30. Lauricella M, Ciraolo A, Carlisi D, Vento R and Tesoriere G: SAHA/TRAIL combination induces detachment and anoikis of MDA-MB231 and MCF-7 breast cancer cells. Biochimie 94: 287-299, 2012.

31. Lee CS, Hall RE, Alexander IE, Koga M, Shine J and Sutherland RL: Inverse relationship between estrogen receptor and epidermal growth factor. Growth Factors 3: 97-103, 1990.
32. Gamou S and Shimizu N: Hydrogen peroxide preferentially enhances the tyrosine phosphorylation of epidermal growth factor receptor. FEBS Lett 357: 161-164, 1995.

33. Haj FG, Markova B, Klaman LD, Bohmer FD and Neel BG: Regulation of receptor tyrosine kinase signaling by protein tyrosine phosphatase-1B. J Biol Chem 278: 739-744, 2003.

34. Chiarugi P: PTPs versus PTKs: the redox side of the coin. Free Radic Res 39: 353-364, 2005

35. Paulsen CE, Truong TH, Garcia FJ, Homann A, Gupta V, Leonard SE and Carroll KS: Peroxide-dependent sulfenylation of the EGFR catalytic site enhances kinase activity. Nat Chem Biol 8: 57-64, 2011.

36. Tamas P, Solti Z, Bauer P, Illes A, Sipeki S, Bauer A, Farago A, Downward J and Buday L: Mechanism of epidermal growth factor regulation of Vav2, a guanine nucleotide exchange factor for Rac. J Biol Chem 278: 5163-5171, 2003.

37. Sheng ZG, Huang W, Liu YX, Yuan Y and Zhu BZ: Ofloxacin induces apoptosis via $\beta 1$ integrin-EGFR-Rac1-Nox 2 pathway in microencapsulated chondrocytes. Toxicol Appl Pharmacol 267: 74-87, 2013. 